Pacific Journal of Mathematic 


\section{ON THE GENERATION OF DISCONTINUOUS GROUPS}

\section{JOSEPH LEHNER}

In a paper in this Journal (v. 11, p. 675) M. I. Knopp remarked that $G(j)$, the principal congruence subgroup of level $j \geqq 2$ of the modular group, can be generated exclusively by parabolic transformations if and only if it is of genus zero. The following natural generalization is easily proved:

Let $\Gamma$ be a horocyclic ${ }^{1}$ group of genus $g$. Then $\Gamma$ possesses a system of generators consisting entirely of parabolic and elliptic elements if and only if $g=0$.

Knopp's result is a special case, since $G(j)$ has no elliptic substitutions.

For the proof we appeal to the classical result that $\Gamma$ has a canonical fundamental region whose sides are conjugated by elliptic and parabolic substitutions and $2 g$ hyperbolic substitutions $A_{1}, B_{1}, \cdots$, $A_{g}, B_{g}$ (cf. [1], p. $182 \mathrm{ff}$ ). These substitutions generate $\Gamma$. If $g=0$, the hyperbolic ones are absent and the conclusion follows.

Conversely, let $\Gamma$ be generated by elliptic and parabolic transformations $T_{1}, \cdots, T_{s}$. Let the domain of existence of $\Gamma$ be, for example, the upper half-plane $H$. Denote by $H^{+}$the union of $H$ and the parabolic cusps of $\Gamma$. If $g>0$ there exists an abelian integral of the first kind, that is, a function $F$ regular in $H^{+}$such that

$$
F(L z)=F(z)+C(L)
$$

for all $L \in \Gamma$. Each $T_{i}$ has a fixed point lying in $H^{+}$. Letting $z$ tend to this fixed point in $(*)$, we see that $C\left(T_{i}\right)=0, i=1, \cdots, s$. Since

$$
C\left(L_{1} L_{2}\right)=C\left(L_{1}\right)+C\left(L_{2}\right),
$$

and the $T_{i}$ generate $\Gamma$, we have

$$
C(L)=0
$$

for all $L \in \Gamma$. The abelian integral $F$ has zero periods and is therefore an automorphic function on $\Gamma$. Since it is regular in the closed fundamental region, it is a constant. Differentiating, we conclude that there are no abelian differentials of the first kind except 0 ,

Received June 15, 1962.

1 A discontinuous group $\Gamma$ is called horocyclic (Grenzkreisgruppe) if there is a fixed disk (or half-plane) preserved by each element of $\Gamma$ and every boundary point of the disk is a limit point of $\Gamma$. 
whence $\Gamma$ is of genus 0 . This completes the proof.

That a group of genus 0 cannot always be generated entirely by parabolic elements is shown by the following example, supplied by Morris Newman. Let $H$ be the group generated by $G=G(3)$ and $T$, where $T \tau=-1 / \tau$. Since $T$ is of period 2 and commutes with $G$, we have

$$
H=G+T G .
$$

Now $G$ is of genus 0 , as is known. Let $f(\tau)$ be a univalent function on $G$ with a simple pole at $\tau_{0} \neq i$. Then $f(\tau)+f(-1 / \tau)$ is univalent on $H$, which is therefore of genus 0 . A parabolic element $P$ of $H$ cannot lie in $T G$, for $P$ has trace \pm 2 whereas $T G \equiv T(\bmod 3)$ has trace divisible by 3 . Hence $P$ is in $G$, and therefore every product of parabolic elements of $H$ is also in $G$. It follows that $H$ cannot be generated by parabolic elements alone.

Instead of $G(3)$ we could also have used $G(4)$ or $G(5)$.

\section{REFERENCE}

1. R. Fricke-F. Klein, Vorlesungen über die Theorie der automorphen Funktionen, vol. 1, Teubner, Leipzig, 1897.

National Bureau of Standards and Michigan State University 


\section{PACIFIC JOURNAL OF MATHEMATICS}

\section{EDITORS}

\section{RalPh S. Phillips}

Stanford University

Stanford, California

M. G. Arsove

University of Washington

Seattle 5, Washington
J. Dugundji

University of Southern California Los Angeles 7, California

Lowell J. Paige

University of California

Los Angeles 24, California

\section{ASSOCIATE EDITORS}
E. F. BECKENBACH
D. DERRY
H. L. ROYDEN
E. G. STRAUS
T. M. CHERRY
M. OHTSUKA
E. SPANIER
F. WOLF

\section{SUPPORTING INSTITUTIONS}

\author{
UNIVERSITY OF BRITISH COLUMBIA \\ CALIFORNIA INSTITUTE OF TECHNOLOGY \\ UNIVERSITY OF CALIFORNIA \\ MONTANA STATE UNIVERSITY \\ UNIVERSITY OF NEVADA \\ NEW MEXICO STATE UNIVERSITY \\ OREGON STATE UNIVERSITY \\ UNIVERSITY OF OREGON \\ OSAKA UNIVERSITY \\ UNIVERSITY OF SOUTHERN CALIFORNIA
}

STANFORD UNIVERSITY

UNIVERSITY OF TOKYO

UNIVERSITY OF UTAH

WASHINGTON STATE UNIVERSITY

UNIVERSITY OF WASHINGTON

AMERICAN MATHEMATICAL SOCIETY

CALIFORNIA RESEARCH CORPORATION SPACE TECHNOLOGY LABORATORIES

NAVAL ORDNANCE TEST STATION

Printed in Japan by International Academic Printing Co., Ltd., Tokyo Japan 


\section{Pacific Journal of Mathematics}

\section{Vol. 13, No. 1 \\ March, 1963}

Frantz Woodrow Ashley, Jr., A cone of super-(L) functions............. 1

Earl Robert Berkson, Some metrics on the subspaces of a Banach space....

Felix Earl Browder and Walter Strauss, Scattering for non-linear wave

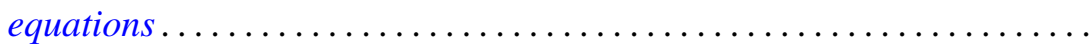

Edmond Darrell Cashwell and C. J. Everett, Formal power series ..........

Frank Sydney Cater, Continuous linear functionals on certain topological

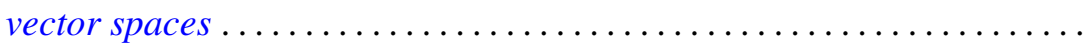

John Douglas Dixon, General group extensions ....................

Robert Pertsch Gilbert, On harmonic functions of four variables with

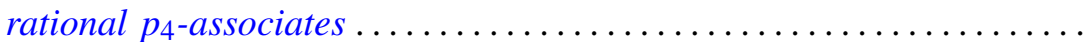

Irving Leonard Glicksberg, On convex hulls of translates ..............

Simon Hellerstein, On a class of meromorphic functions with deficient zeros

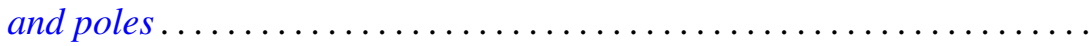

Donald William Kahn, Secondary cohomology operations which extend the

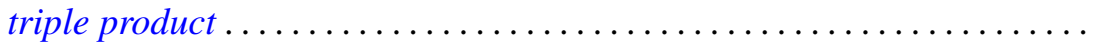

G. K. Leaf, A spectral theory for a class of linear operators .............

R. Sherman Lehman, Algebraic properties of the composition of solutions of partial differential equations ........................... 157

Joseph Lehner, On the generation of discontinuous groups ............. 169

S. P. Lloyd, On certain projections in spaces of continuous functions ...... 171 Fumi-Yuki Maeda, Generalized spectral operators on locally convex spaces ..................................

Donald Vern Meyer, $E^{3}$ modulo a 3-cell

William H. Mills, An application of linear programming to permutation groups.

Richard Scott Pierce, Centers of purity in abelian groups

Christian Pommerenke, On meromorphic starlike functions ...

Zalman Rubinstein, Analytic methods in the study of zeros of

polynomials...

B. N. Sahney, On the Nörlund summability of Fourier series

Tôru Saitô, Regular elements in an ordered semigroup . .

Lee Meyers Sonneborn, Level sets on spheres...........

Charles Andrew Swanson, Asymptotic estimates for limit point

problems .

Lucien Waelbroeck, On the analytic spectrum of Arens . .

Alvin (Murray) White, Singularities of a harmonic function of three

variables given by its series development .............

Kōichi Yamamoto, Decomposition fields of difference sets ...

Chung-Tao Yang, On the action of $\mathrm{SO}(3)$ on a cohomology manifold... 